\title{
PERFORMANCE AND EMISSION ANALYSIS OF BIO- DIESEL FUEL WITH TITANIUM- OXIDE COATED PISTON ON 4-STROKE D.I DIESEL ENGINE
}

\section{NOMENCLATURE \\ CP coated piston \\ NP normal piston \\ $\mathrm{TiO}_{2}$ titanium oxide \\ $\mathrm{Al}_{2} \mathrm{O}_{3}$ aluminum oxide \\ $\mathrm{NOx}$ nitrogen oxide \\ $\mathrm{CO}_{2}$ carbon di-oxide \\ HC hydro-carbon \\ $\mathrm{CO}$ carbon monoxide \\ $\mathrm{GPa}$ gigapascal \\ MPa megapascal}

R. B. Reddy ${ }^{\mathrm{a}}$, and S. S. Reddy

${ }^{\mathrm{a}}$ Institute of Technology (SKIT) Department of Mechanical Engineering Srikalahasteeswara, Srikalahasti, Chittoor (dt) A.P, INDIA rkbreddy111@gmail.com ${ }^{\mathrm{b}}$ Siddarth Institute of Egineering and Technology (SIETK) Department of Mechanical Engineering Puttur, Chittor (dt) A.P, INDIA. Received: May 13, 2017 Revised: May 31, 2017 Accepted: June 16, 2017

\section{ABSTRACT}

Diesel engines are being used extensively for fuel economy but due to gradual depletion of Petroleum resources and increase in exhaust emissions, there is an urgent need for suitable alternative fuels for the diesel engines. As our country is an agricultural country, if the alternate fuels are produced by our farmers it will be beneficial for the country and the farmers also. In recent studies, researchers studied various vegetable oils like canola oil, aloveera oil, soya been oil, flaxseed oil and hone oil etc. Out of all flaxseed oil play an important role as an alternative fuel. But the properties of flaxseed oil are not suitable for the usage in the existing diesel engines without blending with diesel fuel. The performance of the engine depends on the combustion phenomenon and it further depends on the amount of heat retained in the combustion chamber. Hence the present work is planned accordingly to develop an insulated engine by coating the piston with $\mathrm{TIO}_{2}$ material. So that more amount of heat will be retained in the combustion chamber which aids the combustion. Further the performance of flaxseed biodiesel blend namely B10, B20, B30 and B40 are tested and the results are mentioned accordingly.

Keywords: blended oil, exhaust emissions, flaxseed oil, piston crown, performance parameters, $\mathrm{TiO}_{2}$ coating

\section{INTRODUCTION}

The consumption of petroleum fuels has been increased tremendously in both industries and transport sector, which leads for emissions. The alternate fuels should be renewable, easily available, produce low emissions and high performance. An intensive search is being carried in developing an alternate for diesel. Among all, biodiesels are renewable and can be produced easily in rural areas. Since they have properties comparable to diesel fuel, these can be used in diesel engines without much modification in the existing diesel engine. Based on the literature these are clean burning fuels without much harmful emissions. But with the higher temperatures in the combustion chambers the combustion will be complete. In general, the much amount of heat produced is transferred through the piston. Hence in the present work for the retaining of heat in the combustion chamber the piston is coated with an insulated material $\mathrm{TiO} 2$.

\section{Flaxseed Oil}

Flaxseed oil scientific name is Linum usitatissimum, (or) Linaceae. The yellowish drying oil is derived from dried ripe seeds of flax plant through pressing and extraction. Fresh, refrigerated and unprocessed, flaxseed oil is used as nutritional supplement.
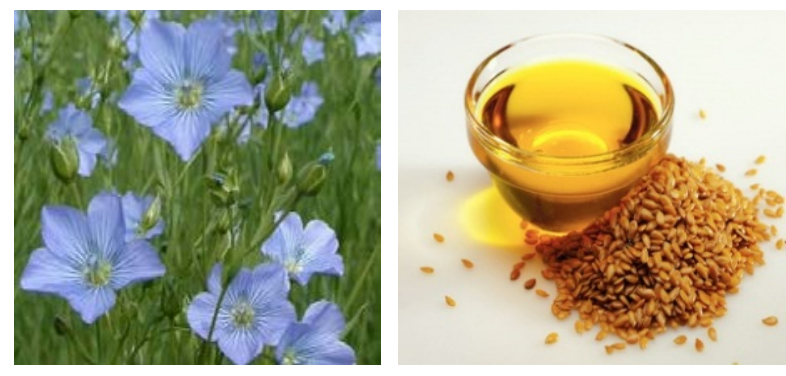

Figure 1. Flaxseed plant and seeds.

It is available in Asian countries. The procedure for the production of flaxseed oil from the plant is 
shown in the following layout.

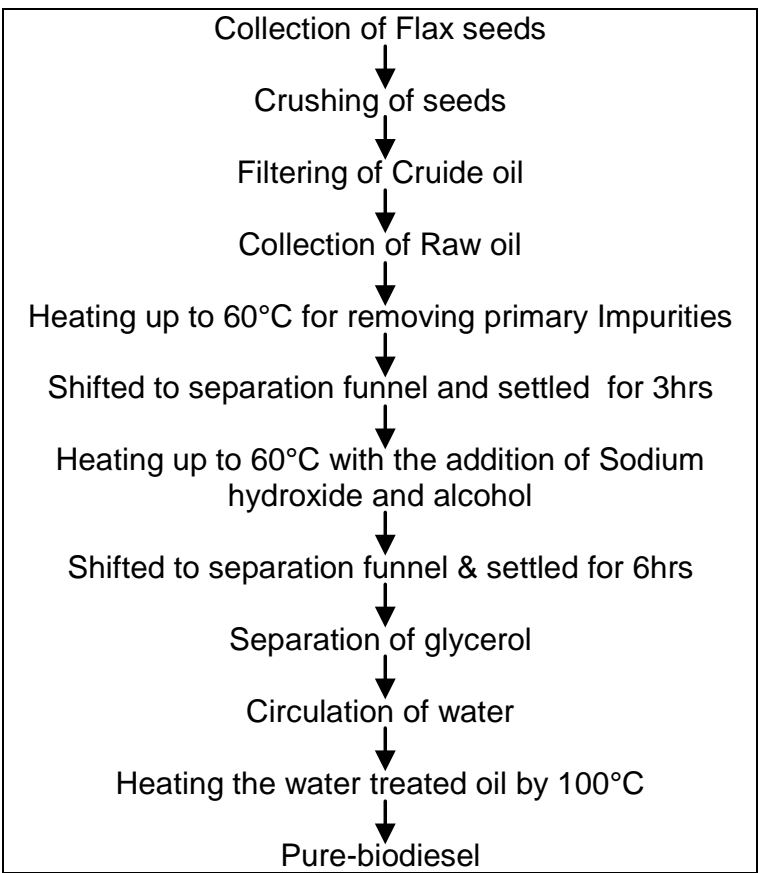

Figure 2. Production process of bio-diesel.

\section{LITERATURE REVIEW}

Considerable amount of work has been done on biodiesel and is represented below. Helmisyah et al. (2012), has studied the performance of engine with PSZ coated piston by compressed natural gas and compared the same with uncoated piston. They concluded that high thermal stresses were induced in the piston and piston crown fails to operate effectively with insufficient heat transfer. Detailed analyses of microstructure, hardness, surface roughness, and interface bonding on the deposited coating were conducted to ensure its quality. The PSZ coated piston demonstrated lesser thermal stresses than the uncoated piston crowns despite a rough surface. Aydin Huseyinet et al. (2013), experimentally investigated the combined effects of thermal barrier coating with zirconium oxide $\left(\mathrm{ZrO}_{2}\right)$ and blending with diesel fuel on usability of vegetable oils in diesel engines. With the engine coating the heat will be retained in the combustion chamber and increases the thermal efficiency and performance of the engine. Further the work was extended with cottonseed oil and sunflower oil blended with diesel fuel and concluded that exhaust emission parameters such as CO, HC and smoke opacity were decreased. Also, sunflower oil blends presented better performance and emission parameters than cottonseed oil blends. Hazaret et al. (2010) studied the effect of $\mathrm{Al}_{2} \mathrm{O}_{3}-\mathrm{TiO}_{2}$ coating in a diesel engine on the performance and emission of corn oil methyl ester and compared the same with uncoated engines. A decrease in engine power and specific fuel consumption, as well as significant improvements in exhaust gas emissions (except NOx), were observed for all test fuels used in the coated engine compared with that of the uncoated engine. Investigations were carried out by Altinet et al. (2001), to study the effects of vegetable oil fuels and their methyl esters with Al-Ti coated piston on a DI, four stroke and single cylinder diesel engine. They concluded that raw vegetable oils can be used as fuel in diesel engines with some modifications and when compared to diesel fuel, a little amount of loss in power was observed and the particulate emissions were higher than that of diesel fuel. Vegetable oil and methyl esters exhibited the performance and emission characteristics closer to the diesel fuel when compared to uncoated piston engine. Giannakos et al. (2002), the physical, chemical and fuel related properties of tobacco seed oil were investigated and suggested that this non edible oil may be an appropriate substitute for diesel fuel.

\section{METHODOLOGY}

\section{Properties of Titanium Oxide}

Thermal and physical properties of titanium oxide materials are found with standard equipment's and are mentioned below.

Table 1. Properties of Ti-O2.

\begin{tabular}{|c|c|}
\hline Chemical formula & Ti-O2 \\
\hline Density & $4.23 \mathrm{~g} / \mathrm{cm}^{3}$ \\
\hline Melting point & $1843^{\circ} \mathrm{C}$ \\
\hline Boiling point & $2972^{\circ} \mathrm{C}$ \\
\hline Thermal Conductivity $\left(25^{\circ} \mathrm{C}\right)$ & $11.7 \mathrm{WmK}-1$ \\
\hline Thermal expansion $\left(\mathrm{RT}-1000^{\circ} \mathrm{C}\right)$ & $9 \times 10-6 /{ }^{\circ} \mathrm{C}$ \\
\hline Hardness & $10290 \mathrm{MPa}$ \\
\hline Modulus of Elasticity & $230 \mathrm{GPa}$ \\
\hline Shear Modulus & $680 \mathrm{MPa}$ \\
\hline Tensile Strength & $367 \mathrm{MPa}$ \\
\hline Compressive Strength & $680 \mathrm{MPa}$ \\
\hline Endurance limit & $330.7 \mathrm{MPa}$ \\
\hline
\end{tabular}

\section{Coating Procedure}

The following procedure was adopted during $\mathrm{TiO}_{2}$ coating process:

$>$ The substrates were cleaned and roughened using emery paper (P220) and grit-blasted using sand blast system with pressure 4-6 bar by sand blast device.

$>$ The grit-blasted substrates were cleaned using a hydrous ethanol alcohol and dried at $200^{\circ} \mathrm{C}$ by a furnace for $30 \mathrm{~min}$.

> The TiO2 powder with particle size ranging from 50-90 $\mu \mathrm{m}$ was used for piston coating.

$>$ The substrate is fixed on the flange normal to the flame and powder flow.

$>$ The cooling system (air compressor) is switched on to cool the substrates and protect it from melting during spraying process.

$>$ The bond powder required for the first layer is 
loaded into the holder.

> The substrate is heated to a suitable temperature around $\left(300^{\circ} \mathrm{C}\right)$ by the flame.

$>$ The coating process is started by moving a lever on the hopper to allow all the powder $\left(\mathrm{TiO}_{2}\right)$ to flow through the holder with the flame. A distance of about $(20 \mathrm{~cm})$ between the flame and the specimen is maintained until $350-400$ $\mu \mathrm{m}$ thickness for piston is obtained.

$>$ For adhesion process, it is to be preheated to about $1500^{\circ} \mathrm{C}$ directly after completing the spray process.

$>$ The flame is then withdrawn gradually away from the valve to minimize thermal shock.

$>$ After the thermal coating process is completed, the excess parts of coating material are removed by grinding process to avoid crankshaft breakdown.
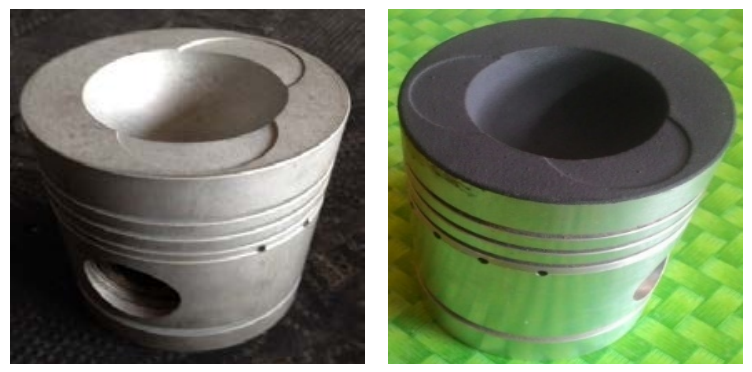

Figure 3. Pistons before and after coating with $\mathrm{TiO} 2$ powder.

\section{RESULTS AND DISCUSSIONS}

In order to analyze the performance and emission characteristics of diesel engine, an experimental set-up was developed. In the present work, titanium oxide $\left(\mathrm{TiO}_{2}\right)$ was coated on piston crown and flax seed oil was used as biodiesel on volume basis. The experiment was carried out on a single cylinder water cooled direct injection diesel engine. Eddy current dynamometer is used for loading i.e. electrical loading. The experimental set up is as shown in the following figure.

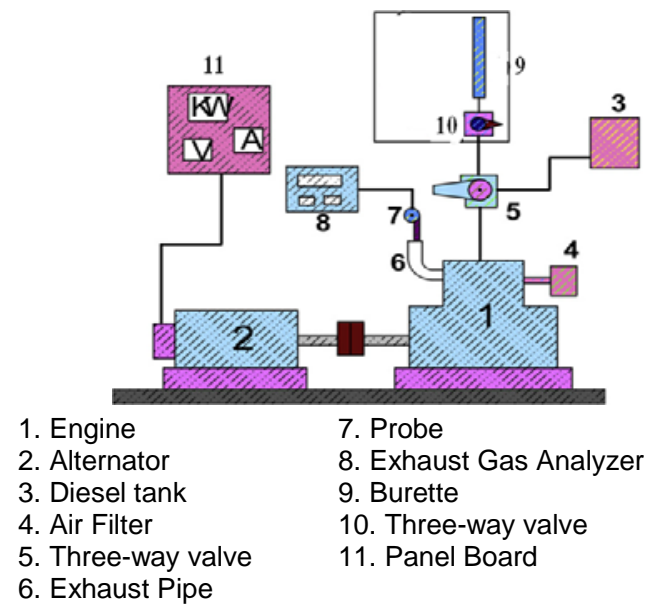

Figure 4. Experimental setup of 4-Stroke diesel engine.
Table 2. Engine specifications.

\begin{tabular}{|c|c|c|}
\hline S. No. & Particulars & Specifications \\
\hline 1 & Make of the Engine & Kirloskar \\
\hline 2 & Cylinders arrangement & Vertical \\
\hline 3 & No. of cylinders & One \\
\hline 4 & Lubricants & SAE 20/SAE 40 \\
\hline 5 & Bore & $85 \mathrm{~mm}$ \\
\hline 6 & Stroke length & $110 \mathrm{~mm}$ \\
\hline 7 & Rated speed & $1500 \mathrm{rpm}$ \\
\hline 8 & Rated power & $5 \mathrm{HP}$ \\
\hline 9 & Type of cooling & Water cooling \\
\hline
\end{tabular}

\section{Brake Thermal Efficiency}

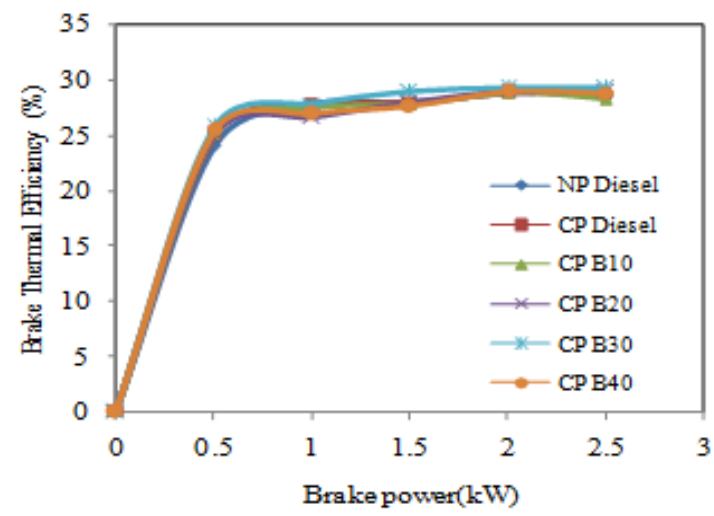

Graph-1. Variations of Brake thermal efficiency with Brake Power.

The graph-1 shows the variation of brake thermal efficiency at rated load. As the properties of flaxseed biodiesel and diesel are nearer, there is much variation in the thermal efficiency at any load. Among all it is clearly observed that the coated piston engine of B30 blend gives higher brake thermal efficiency compared to normal piston engine. The efficiency of B30 and B40 blends with coated piston are $1.365 \%$ and $1.16 \%$ higher than the normal piston engine respectively. The performance of the remaining blends is in between B30 and B40 blends performance.

\section{Brake Specific Fuel Consumption}

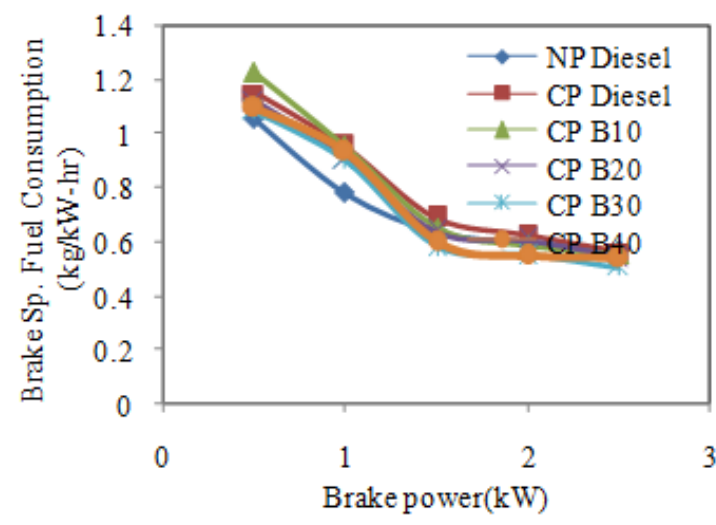

Graph-2. Variations of BrakeSp Fuel Consumption with Brake Power. 
The variation of B.S.F.C with brake power is shown in the graph-2. With the complete combustion in the chamber, amount of power generation increases and B.S.F.C. decreases. It is clearly observed that the coated engine piston of B30 blend oil gives lower B.S.F.C. compared to normal piston engine. This was because of $\mathrm{TiO}_{2}$ material which acted as thermal insulator and aided for complete combustion. For coated piston engine B30 and B40 blended oil was reduced by $10.17 \%$ and $6.50 \%$ respectively compared to normal piston engine.

\section{Carbon di-oxide Emission}

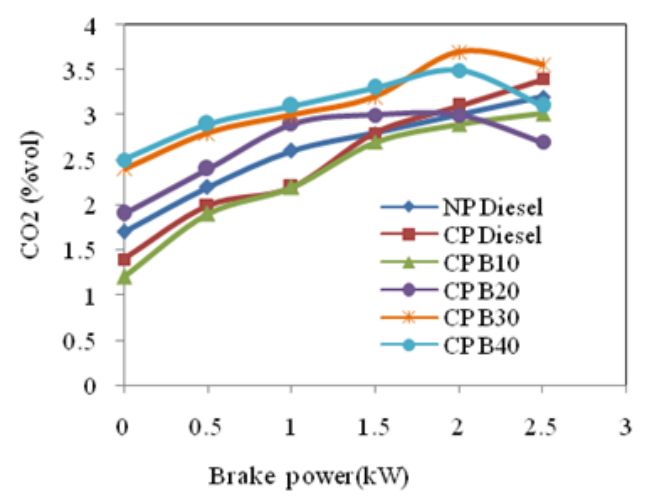

Graph-3.Variations of CO2 emissions with Brake Power.

With the complete combustion of the fuel in the combustion chamber, $\mathrm{CO}$ will react with the inherent oxygen in the biodiesel and converts into $\mathrm{CO} 2$. Hence as the load on the engine increases CO2 content also increases. This is illustrated from the graph-3. It is evident that the coated piston engine of B30 blend oil gives higher CO2 emission and lowest with B40 blended oil compared to normal piston engine. The emissions of remaining blends are in between these two. For coated piston engine with B30 and B40 blended oil, the CO2 emission increased by $13.51 \%$ and $8.10 \%$ than normal piston engine.

\section{NOx Emission}

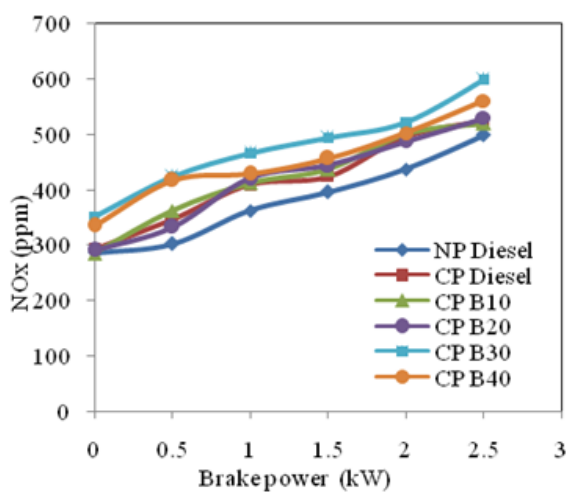

Graph-4.Variations of $\mathrm{NO}_{\mathrm{X}}$ Emissions with Brake Power.
Nitrogen acts as an inert gas at lower temperature and will be active at higher temperatures. The formation of NOx emissions depends on the combustion phenomenon and the amount of oxygen content available in the engine. If the combustion is complete the amount heat generation inside the combustion chamber is also more. The graph-4 illustrates the variation of $\mathrm{NO}_{\mathrm{X}}$ emissions with load. It is clearly observed that the coated piston engine with $\mathrm{B} 30$ blend oil gives higher $\mathrm{NO}_{\mathrm{X}}$ emissions, because of its inherent oxygen content and combustion to that of normal piston. For B30 and $\mathrm{B} 40$ blended oil on coated piston engine, the $\mathrm{NO}_{\mathrm{X}}$ emissions increased by $16.72 \%$ and $6.35 \%$ to normal piston engine respectively. For all the other blends it is in between the two blends.

\section{HC Emission}

The formation of $\mathrm{HC}$ emissions in the engine depends on the wall quenching, incomplete combustion and improper mixing of air and fuel. The coated piston acts as an insulator for the heat transfer through the piston and retain the heat inside the chamber. With the good amount of heat complete combustion of the fuel takes place and results high heat production. The variation of HC emissions with brake power is illustrated in the graph-5. It is observed that the coated piston engine of B30 blend oil gives less HC Emission when compared to normal piston engine. As the load increases the fuel also increases and the oxygen content available also increases which enhances the formation of $\mathrm{HC}$ emissions. For the coated piston engine with B30 and B40 blended oil, the HC Emissions reduced by $19.04 \%$ and $10.52 \%$ to normal piston engine respectively.

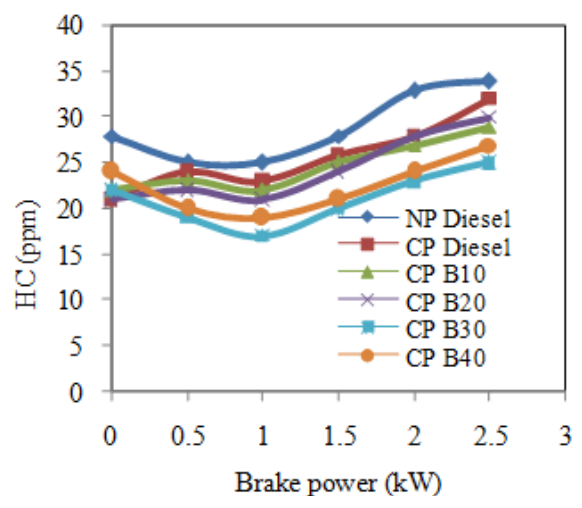

Graph-5.Variation of HC Emissions with Brake Power.

\section{CONCLUSIONS}

In the present work, the performance of the diesel engine is studied with ceramic coating $\left(\mathrm{TiO}_{2}\right)$ on the piston with various blended oils of flaxseed biodiesel. The obtained results for flaxseed oil and 
their blends with diesel were compared with the diesel. Based on the performance and emission characteristics, B30 blended oil on coated piston engine gives the better performance and emissions than the normal piston engine.

The folowing results are obtained by experimental work.

- Brake specific fuel consumption for the flax seed oil blend with diesel (B30) is $0.503 \mathrm{~kg} / \mathrm{kw}$ $\mathrm{hr}$. It is lower than the normal piston engine.

- The brake thermal efficiency of the engine enhances with good combustion in the chamber. For B30 blend with coated piston gives high efficiency compared to other blends. Brake thermal efficiency of B30 blend of coated piston engine is $29.3 \%$ and increased with $1.365 \%$ and $1.16 \%$ at rated load for coated piston of diesel and B40 oil.

- With inherent oxygen in biodiesel and high temperature due to coating on the piston, CO2 emission is high for coated piston with B30 and is $3.2 \% \mathrm{vol}$ and then increased slightly for normal piston diesel engine and coated piston engine blend (B40) is $13.51 \%$ and 5.40 respectively.

- NOx emissions are higher with higher temperatures in the combustion chamber. For B30 of coated piston engine, the NOx emission is $598 \mathrm{ppm}$ and is increased by $16.72 \%$ and $12.54 \%$ at rated load to normal piston and coated piston engine respectively.

- HC emission of flax seed oil with diesel fuel of $\mathrm{B} 30$ blend gives less emission and is $17 \mathrm{ppm}$. It is reduced as the temperature inside chamber increases.

From the above analysis the main conclusion is that flax seed oil blends with diesel are suitable substitute for diesel as they produce lesser emissions than diesel and the ceramic coated piston engines enable the use of low cetane fuels with its high operating temperatures have satisfactory performance and emission characteristics.

\section{REFERENCES}

Beg, R. A., Bose, P. K., Ghosh, B. B., and Banerjee, T. Kr., 2013, Aydin Huseyin Examined the "Combined Effects of Thermal Barrier Coating and Blending with Diesel Fuel on Usability of Vegetable Oils in Diesel Engines”, Applied Thermal Engineering, Vol. 51, pp. 623-629.

Helmisyah A. J., and Ghazali M. J., 2012, Characterization of Thermal Barrier Coating on Piston Crown for Compressed Natural Gas Direct Injection (Cngdi) Engines, Asian International Journal of Science and Technology in Production and Manufacturing Engineering, Vol. 5, No. 4, pp. 73-77.

T. Karthikeya Sharma, 2014, Performance and Emission Characteristics of the Thermal Barrier Coated SI Engine by adding Argon Inert Gas to
Intake Mixture, Journal of Advanced Research, Vol. 6, pp. 819-826.

Kimura, S., Matsui, Y., and Ltoh, T., 1992, Effects of Combustion Chamber Insulation on the Heat Rejection and Thermal Efficiency of Diesel Engines, in: International \& Congress and Exposition, Detroit, Michigan February, USA, pp. 24-28.

Nabi, N., and Hoque, N., 2008, Biodiesel Production from Linseed Oil and Performance Study of a Diesel Engine with Diesel Bio-Diesel, Journal of Mechanical Engineering, Vol. 39, No. 1, pp: 40-44.

Altin R., Cetinkaya S., and Yucesu, H. S., 2001, The Potential of using Vegetable Oil Fuels as Fuel for Diesel Engines, Energy Conversion and Management, Vol. 42, pp. 529-538.

Giannakos P. N., Zannikos F., Stournas S., Lois E., and Anastopoulos G., 2002, Tobacco Seed Oil as an Alternative Diesel Fuel: Physical and Chemical Properties, Industrial Crops and Products, Vol. 16, pp. 1-9.

Hazar H., 2010, Cotton Methyl Ester usage in a Diesel Engine Equipped with Insulated Combustion Chamber, Applied Energy, Vol. 87, pp. 134-40.

Jeffrey, S. G., and Nancy, A. M., 2009, The Impacts of Combustion Emissions on air Quality and Climate - From Coal to Biofuels and Beyond, Atmospheric Environment, Vol. 43, pp. 23-36.

Karabektas, M., Ergen, G., and Hosoz, M., 2008, The Effects of Preheated Cotton Seed oil Methyl Ester on the Performance and Exhaust Emissions of a Diesel Engine, Applied Thermal Engineering, Vol. 28, pp. 2136-2143. 